\title{
Correction to: Proposal of a new nomenclature for introns in protein-coding genes in fungal mitogenomes
}

Shu Zhang ${ }^{1}$ and Yong-Jie Zhang ${ }^{2^{*}}$

\section{Correction to: IMA Fungus (2019) 10:15 \\ https://doi.org/10.1186/s43008-019-0015-5}

The published article (Zhang and Zhang 2019) includes an incorrect sequence. The erroneously indicated nad4L sequence NC_001715 (GenBank accession number) should be replaced by NC_036382 (GenBank accession number) in additional file 1 .

- Incorrect sequence:

">NAD4L_NC_001715

ATGCTTTTAGAAATAATAACAGCTTATAAA ATAGGAACAATCTTATTTTTAATTGGAATTTT AGGTTTCATTATCAATAGACAAAATATTCTTT TACTTATTATCTCTATTGAAATGACTTTATTA GCTATTAGTTTTATTATTATTTGTTCTGCTCT TTTCCTTGATGATTCTGCAGCAGCTTGTTTTT CACTTTATATTTTAGCTCTTGCTGGTTCAGAAG CTGCAATTGGTCTTTCACTTTTAGTTTTATTCCATAGATTTAGAGGATC

AGTATTAATTTCAGCTTCTCGACAATAG"

- Correct sequence:

">nad4L_NC_036382

ATGAGTTTAACTTTAGTACTTTTTTTAATAGG AATCTTAGGATTCGTATTTAATAGAAAAAATATA ATATTAATGCTTATTTCTATAGAAATAATGCT ATTATCTATAACATTTTTAATATTGGTAAGTT CTATTAATCTTGACGATATAATAGGACAAACA

The original article can be found online at https://doi.org/10.1186/s43008 019-0015-5

* Correspondence: zhangyj2008@sxu.edu.cn

${ }^{2}$ School of Life Science, Shanxi University, Taiyuan 030006, China

Full list of author information is available at the end of the article
TATGCTATATACATTATAGTAGTTGCTGGTGC AGAATCTGCTATCGGTTTAGCTATTTTAGTAGC TTTTTATAGACTAAGAGGAAGTATCGCAATAGAA TATAAATAA"

To be in concordance with this change, "P263" in the nad4L column should be changed to "P239" in Table 3.

The authors would like to apologise for any inconvenience caused.

\section{Author details}

'Institute of Applied Chemistry, Shanxi University, Taiyuan 030006, China.

${ }^{2}$ School of Life Science, Shanxi University, Taiyuan 030006, China.

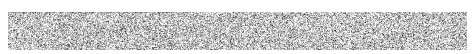

\section{Reference}

Zhang, Zhang (2019) Proposal of a new nomenclature for introns in proteincoding genes in fungal mitogenomes. IMA Fungus 10:15. https://doi.org/10. 1186/s43008-019-0015-5

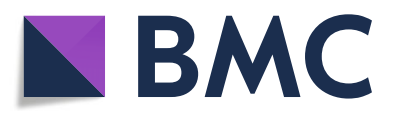

( The Author(s). 2020 Open Access This article is licensed under a Creative Commons Attribution 4.0 International License, which permits use, sharing, adaptation, distribution and reproduction in any medium or format, as long as you give appropriate credit to the original author(s) and the source, provide a link to the Creative Commons licence, and indicate if changes were made. The images or other third party material in this article are included in the article's Creative Commons licence, unless indicated otherwise in a credit line to the material. If material is not included in the article's Creative Commons licence and your intended use is not permitted by statutory regulation or exceeds the permitted use, you will need to obtain permission directly from the copyright holder. To view a copy of this licence, visit http://creativecommons.org/licenses/by/4.0/. 